\title{
A microsimulation analysis of the 2006 regime change in the Dutch
}

\author{
disability scheme
}

\author{
J.M. van Sonsbeek, R.H.J.M. Gradus ${ }^{1}$
}

\begin{abstract}
This paper introduces a microsimulation model that simulates the budgetary impact of the 2006 regime change in the Dutch disability scheme. A dynamic population model fits the case of the disability benefits the best. As opposed to macro forecasts, a microsimulation can answer questions about the individual or meso income effects, the exact distribution of expenses among different benefits and the time path of the savings. The introduction of the proposed system change decreases the number of disability benefits by more than $25 \%$ from 2020 onwards and reduces total costs by almost $€ 2$ billion or $20 \%$. Based on the better incentive structure, participation will increase and boost GDP. Microsimulation can be used to pick the winners and losers of the new system and give the time path of the savings. It is shown that for almost all partially disabled that are working, the total discounted income after the system change is as large as or larger than before the system change, for the non-working total discounted income is lower.
\end{abstract}

\section{Introduction}

An important benefit program in the Netherlands is the Disablement Benefits Act (Wet op de arbeidsongeschiktheidsverzekering or WAO). This disability insurance covers the employee's loss of income due to long-term sickness and disability. From its introduction in 1967 until the beginning of the nineties, there has been a steady increase in the number of disability benefit recipients. This increase coincided with a steady rise in unemployment and a drop in labour market participation (Westerhout, 2001). This led to the belief that disability schemes have been used as a labour market exit route. Between 1994 and 1996 the number of disability recipients decreased slightly. This decrease was due to a tightening of the eligibility criteria in 1993 - in particular the definition of disability - and (re)assessments based on the stricter criteria. Between 1996 and 2003 the number of benefits rose again, this time coinciding with an economic boom. In 2003, the number of disability recipients approached 1 million ( $13 \%$ of the labour force). The disability rate in the Netherlands is among the highest in the world (OECD, 2003). Especially women and older workers have a higher chance of getting disabled. Therefore, from the point of view of an ageing society and an increasing share of women in the labour force, it has been forecasted that the amount of disability recipients will increase in the near future and will surpass the level of one million recipients.

Contrary to other European countries the Dutch Disability Insurance Act covers both work-related injury (risque professionnel) and non-work-related injury (risque social). It

\footnotetext{
${ }^{1}$ The authors are affiliated to the Ministry of Social Affairs. Second author is also affiliated to Vrije Universiteit Amsterdam. The views expressed in this paper are the authors' own and should not be attributed to the Ministry of Social Affairs. Valuable comments have been received from Arjan Wojcik, Han Bakkum, Marcel Einerhand (Ministry of Social Affairs), Chris van Raalte (Ministry of Justice), Wim Zwinkels, Jan Besseling (TNO), Frans Suijker, Pierre Koning (CPB), Ed Berendsen (UWV) and Arie Kapteijn (Tilburg University). We would also like to thank Susanna Schaap (Ministry of Social Affairs) for her assistance in correcting the text and preparing the appendix.
} 
allows access into the scheme without taking into account the recipient's previous working history. Moreover, its access level is low as employees already receive a benefit as soon as their earning capacity is reduced by only $15 \%$ due to long-term sickness or disability. In general the disability benefit is permanent and, is at least as high as other social security benefits such as the unemployment benefit and social assistance (see also Kapteyn and de Vos, 1997). This is why the disability insurance in the past few decades has become a very popular arrangement for early retirement. As a result, the government tried to reduce benefit levels in 1993, by limiting the duration of wage-based benefits. In response, most employees had taken an additional (private) insurance policy to cover the risk of this reduction in insurance benefit. Therefore, the number of disability benefit recipients continued to increase at the end of the nineties.

At the beginning of 2001, a group of experts led by Mr. Donner was commissioned. The recommendations of this group are based on the premise that recovery and reintegration of available labour capacity has the highest priority with high responsibility resting with both the employers and employees. In response to this proposal, in 2002 the Social-Economic Council (SER) published an agreement accepting the basic ideas of the so-called Donnerproposal. In September 2003 the Dutch government proposed a major regime change in disability benefits, mainly based on the SER-agreement. The government decided to limit eligibility by tightening entry conditions and reducing benefit levels for partially disabled. Moreover, applications for disability benefits will be subjected to a more rigorous screening of the loss in earnings capacity, and the primary responsibility of employers and employees for limiting sickness absence will be extended from one year to two years. Currently, these proposals are being discussed in parliament. The new Disability Act will be in force from January 1, 2006 onwards whilst the extension of the responsibility of employers and employees for limiting sickness absence has already been in force from January 1, 2004 and the more rigorous screening of the loss in earnings capacity has been in force from October 1 , 2004.

For our discussion it is important to comprehend what kind of impact the different parts of this new Act will have. For this reason, a microsimulation model is developed and this paper discusses the forecasting technique used. Similar attempts have been made to build a Dutch microsimulation model for evaluating social security schemes (e.g. Nelissen, 1991 and Nelissen, 1993).

The paper is structured as follows. In the first paragraph we discuss the current system of disability benefits and the proposed regime change. In the second paragraph we discuss microsimulation and the different kinds of simulation models. We explain our model choice and its design. In the third paragraph we discuss the implementation of our simulation model, including the preparation of the data, the behavioural assumptions and the validation of the model. In the fourth paragraph the results of the simulation model are discussed. We focus both on macro-results (total number of disability benefits, total cost) and on micro-results (spread in changes in individual incomes). Finally, we conclude and introduce some proposals for future research on this topic in the fifth paragraph. 
A microsimulation analysis of the 2006 regime change in the Dutch disability scheme

\section{Disability benefits in the Netherlands}

\subsection{Current system of disability benefits}

At the moment, workers below the age of $65^{2}$ in the Netherlands are entitled, in case of full disablement, to a benefit of $70 \%$ of their previous earnings, called $\mathrm{WAO}^{3}$. After a couple of years, depending on the age of the person, this benefit is reduced to a lower level (second phase $^{4}$ ). This follow-up benefit can be drawn until the age of 65 . In practice, most employers supply employees with additional benefits agreed upon in collective agreements in order to narrow the gap between the lower level in the second phase and the higher level in the first phase. Currently, for $80 \%$ of the employees, the level of the disability benefit for the fully disabled is permanently $70 \%$ of the former wage.

In case of partial disablement, the same rules apply, but instead the amount of benefit is proportional to the grade of disability. In case of partial disablement the disability benefit can be increased with an unemployment benefit, called WW. This benefit lasts for a limited, age-dependent period of time, ranging from 0.5 to 5 years, and is therefore less attractive than the disability benefit (see table 1). When the WW benefit has come to an end, the partially disabled are also entitled to another unemployment benefit, called IOAW (The Provision for Older and Partly Disabled Unemployed Employees). IOAW depends on the income of the whole household, but - contrary to the normal social assistance called WWB - it does not depend on household wealth ${ }^{5}$.

More than half of the partially disabled are actually working part-time. When the total amount of disability benefit, unemployment benefit and wage is below the social minimum level, an additional benefit can be supplied to top-up the benefit to the minimum level. This benefit is called TW (The Supplementary Benefits Act). However, entitlement to such a TWallowance is dependent on the income of the whole family. Thus, contrary to disability benefits, household income is now taken into account.

Table 1: Disability benefits and possible supplements in the Netherlands

\begin{tabular}{|l|l|l|l|l|}
\hline Benefit & & Duration & $\begin{array}{l}\text { Maximum (2003) } \\
\text { (for a single) }\end{array}$ & Conditions on benefit \\
\hline WAO & Disability benefit $-1^{\text {st }}$ phase & $0-6$ years & $€ 30,639$ & none \\
\hline WAO & Disability benefit $-2^{\text {nd }}$ phase & permanent & $€ 11,474 / 30,639$ & none \\
\hline WW & Unemployment benefit & $1 / 2-5$ years & $€ 30,639$ & none \\
\hline TW & Supplement to WAO/WW & $\begin{array}{l}\text { depends on duration } \\
\text { of WAO/WW }\end{array}$ & $€ 3,442$ & partner income \\
\hline IOAW & $\begin{array}{l}\text { Conditional unemployment benefit } \\
\text { for the older and partially disabled }\end{array}$ & permanent & $€ 11,474$ & partner income \\
\hline WWB & Social assistance & permanent & $€ 11,474$ & $\begin{array}{l}\text { partner income, } \\
\text { household wealth }\end{array}$ \\
\hline
\end{tabular}

In the Netherlands there also is a benefit called WAZ, for the disabled self-employed and a benefit called Wajong, for the young handicapped. These two benefits each provide an individual income of at most the social minimum ( $€ 11,474,70 \%$ of the minimum wage, which in 2003 was set at $€ 16,391$ ). They are more attractive than social assistance because they do not depend on partner income or household wealth. In 2003, 56,000 people received a

\footnotetext{
${ }^{2}$ All persons aged 65 or over are entitled to the same general old-age pensions (AOW) and other social security benefits as the disability benefit will expire when someone turns 65 .

${ }^{3}$ The maximum benefit height is $€ 30,639$ per year. This level is approximately 2 times the minimum wage and is indexed by the average wage increase each year. .

${ }^{4}$ See table 1 .

${ }^{5}$ If net household income exceeds the social assistance level, no IOAW benefit is granted.
} 
WAZ-benefit and 138,000 people received a Wajong-benefit. The number of Wajong-benefits is expected to grow steadily to over 200,000 in 2020.

The WAZ-benefit ceased to exist in august 2004 because, according to the government, the self-employed are supposed to be able to insure themselves. Only the existing WAZ-cases keep their entitlement to a disability benefit. In 2003, 786,000 people received a WAO benefit in the Netherlands. In this period more than $13 \%$ of the labour force received a disability benefit and when compared to other OECD-countries this level is extraordinarily high (OECD, 2003). The OECD stresses that the current system provides recipients with little incentive to work and recommends therefore more emphasis on getting disabled persons back into the workforce.

\subsection{Regime change proposed, from 2006 onwards.}

The new system aims at increasing the financial incentives for employees in order to avoid disability and to stimulate labour participation in case of a partial disability. Instead of one general disability benefit law, the population of disabled is subdivided into three categories.

1) People who are fully disabled and have no or only a slim chance of recovery will be granted a disability benefit with probably a higher benefit level than before ${ }^{6}$. The lower second phase benefit is skipped for this group ${ }^{7}$.

2) People who are partially disabled (with a degree of disablement of at least 35\%) or have a good chance of recovery, will be granted either a supplement to the wage they are earning (in case they are working) or qualify for an unemployment benefit with the conditions that apply to it. After expiration of the unemployment benefit, the benefit equals the share of the social minimum level that corresponds with their degree of disability. So, in the new system disabled people who are partially working will be rewarded more than in the old system.

3) People who are partially disabled with a degree of disability lower than $35 \%$ will not have access to disability benefits anymore. These people are supposed to be able to find their way through the labour market themselves, preferably with the same employer as before. For this group, the incentives to work are also encouraged.

Furthermore, in order to keep the first category reserved for people that really are fully disabled, the entrance examinations will be altered. The current medical examination has numerous restrictions on the assessment of labour capacity. These restrictions allow a large number of people to keep receiving a full benefit, some of whom are still able to work. In the new system, it will be more difficult to access the first category and be entitled to full benefits. The alteration of the entrance examinations has already been in force from October 1, 2004, anticipating the new Disability Act.

\footnotetext{
${ }^{6}$ According to the proposal, the benefit level will be raised from $70 \%$ to $75 \%$, if in 2007 the number of fully disabled entering the scheme will be less than 25.000 .

${ }^{7}$ However, most employees have taken out an additional insurance to narrow the gap between the benefit height in the first and the second phase (see paragraph 1.1).
} 
Figure 1: Proposed regime change in disability benefits

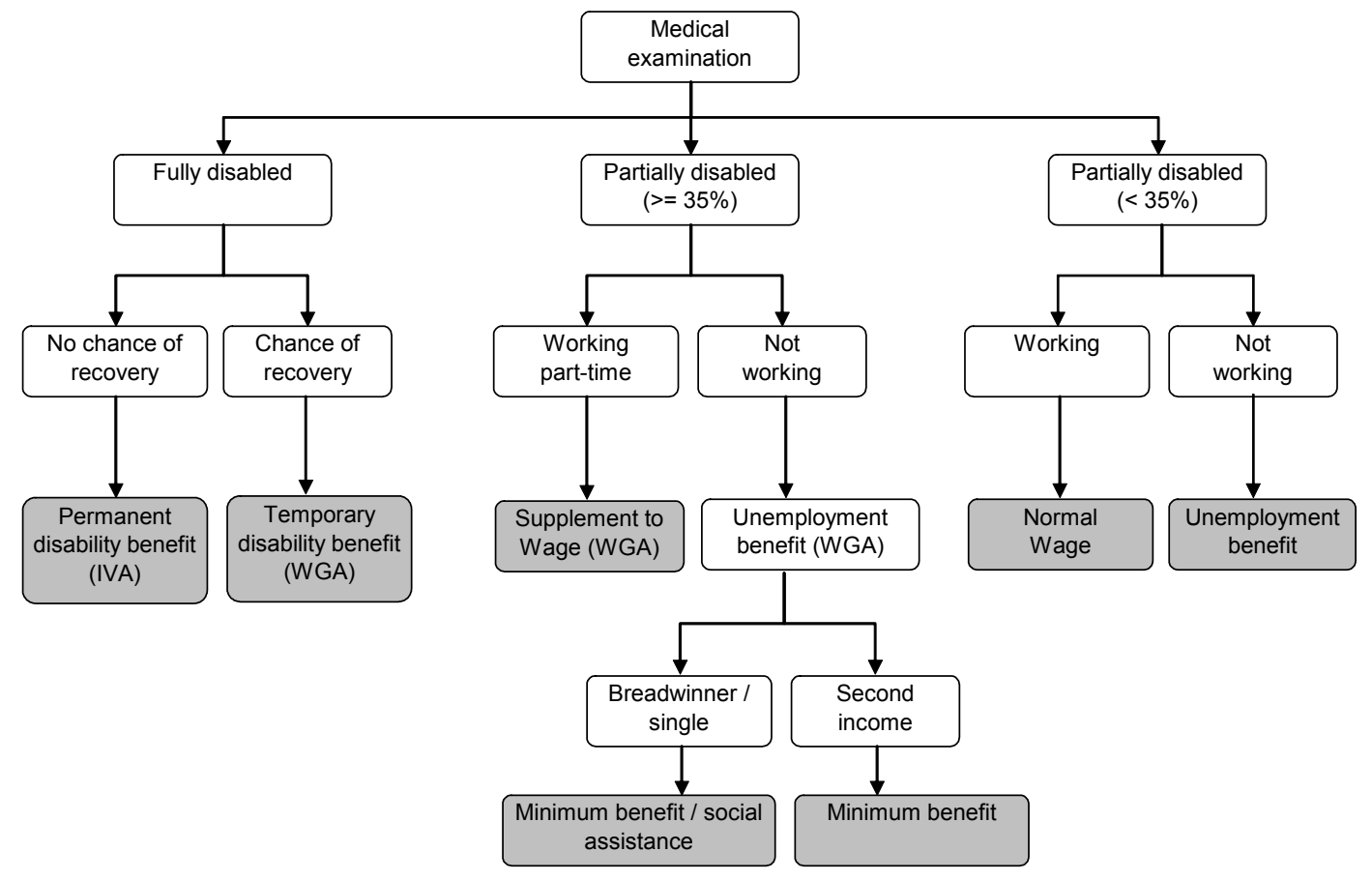

\subsection{Predictions of the regime change effects at the macro level}

Macro forecasts of the effects of the regime change have been calculated by the Netherlands Bureau for Economic Policy Analysis (CPB, $\left.2002^{8}\right)$. CPB expected a decrease in cost of benefits of $€ 2$ billion. They have used an approach in which the long-term cost of the current system are calculated by subdividing the most recent inflow cohort into the relevant subgroups (the shaded boxes from figure 1) and by multiplying the average group sizes with their average benefit heights and average benefit durations. The direct effects of the new system are quantified the same way. The behavioural effects of the new system are calculated using an income elasticity. For each subgroup the average total discounted income during the period of disability was estimated for both the current and the new system. The difference between either the increase or decrease in total discounted income is multiplied by the elasticity in order to forecast the volume effects of such a change. According to analyses made by the CPB (see CPB (2002)) an income elasticity of 1.5 can be applied to measure the volume effects of such an income mutation for disability benefits. This implies that a $1 \%$ decrease in replacement rate leads to a $1.5 \%$ decrease of the number of benefits and a $1.5 \%$ rise of the number of working people. This elasticity is based on several studies done, in particular one, on a sudden increase in benefit levels in Canada (Gruber, 2000).

Though useful for a global view of cost effects and therefore sufficient for the macro calculations of the coalition agreement, this method has some important limitations. Being a macro-method all data used are group averages. But the groups are very diverse, for example with respect to income ranging from low incomes of breadwinners who already receive other benefits to high incomes of people who also have an income earning partner. In this method financial incentives are the only drivers for behavioural effects. Another disadvantage of the method is that each subgroup is seen as an independent entity that interacts with the labour

\footnotetext{
${ }^{8}$ These forecasts are based on the regime change proposals in the coalition agreeement of the cabinet Balkenende I. These proposals are slightly different from the current proposals.
} 
market only, whereas shifts to other subgroups are not taken into account. If, for example, policy measures are implemented that cut the benefits of non-working partially disabled, they are assumed to resume working fully, whereas a shift to working partially and still receiving a partial benefit would seem more plausible.

\section{The Microsimulation model}

\subsection{Microsimulation versus cell-based macro-forecasts}

Usually, system changes are evaluated using cell-based macro-forecasts like the one discussed in paragraph 1.3. These forecasts are reasonably adequate in predicting total structural effects of policy measures but they have difficulties in answering commonly asked questions about the individual or meso income effects, the exact distribution of expenses among different benefits and the time path of the savings. Taking the case of the proposed regime change, the main questions to be asked are what the long-term income effects are for specific groups of disabled (employed and unemployed, men and women, older and younger, partially and fully disabled) and what the distribution of expenses should look like among different benefits in order to make sure that no cost increase for either employers, employees or government would occur. Because of the large number of subgroups that arise when taking into account all the relevant characteristics, these cell-based approaches become problematic when the subgroup size becomes very small. For example, when distinguishing between men and women, 5 age-classes, 8 classes of disability, working and unemployed, at least 3 different household types, the existence of employer's supplements and the existence of enough working history to be entitled to certain benefits, almost 2,000 subgroups would develop.

A microsimulation model takes micro-level units, like individuals, as the basic units of analysis. Microsimulation can have an important added value in answering questions like the ones mentioned above, especially in a complex social security benefit structure. This is the case in the Netherlands, where many combinations of benefits are possible, and where benefit heights depend on many factors like age, working history and household income and wealth. Caldwell and Morrison (2000) give some examples of analyses in which microsimulation should be preferred above macro-forecasts. These include analyses of projected winners and losers of alternative policies on a period-specific or lifetime basis, analyses simultaneously focused on families and individuals, and quantification of incentives to work at particular lifecourse or period junctures. All examples apply to the analysis of the system change in disability benefits. The distribution in time of the cost of benefits (welfare payments) among the many different benefits appeared to be too complex for the macro-models. Therefore we have developed a microsimulation model using data sources on personal level that only recently became available.

\subsection{Model choice}

There are many classes of microsimulation models. Spielauer (2002) distinguishes between static and dynamic models, forecasting and explanatory models, generalised and specialised models, cohort and population models. The choice of model should match its purpose. A model built to forecast the effects of a change in the disability benefit system should evidently be a specialised forecasting model. This leaves the choice between a static and a dynamic model, a cohort and a population model respectively. 
In a static model the characteristics of the persons in the simulation, like age, are fixed. Ageing effects can only be approached by reweighing the dataset at each time step. In a dynamic model the characteristics of the persons in the simulation change over time. Dynamic models consider both first- and second-order effects of policies as behavioural effects may be included. A static model can be appropriate when system dynamics (like ageing) are not relevant to the policy measures, e.g. in case of short-term effects of fiscal policy changes. Otherwise, a dynamic model is preferred. For the case of the disability benefits, we are interested in the long-term effects of the system change, including behavioural effects, thus making a dynamic model the appropriate choice.

In a population model, a whole population is simulated. The model starts off with a sample of the population and then models their life and earnings histories over some period of time (O'Donoghue, 2000). In a population model people leave the simulation if, for example, they die, and new cases, for example births, can be added to the simulation. In a cohort model, one single cohort is simulated over its entire lifetime, without the possibility of new cohorts being added. The cohort model starts off with a sample of individuals aged 0 at a particular point in time and models each individuals life and earnings history.

Often, a cohort model is chosen because its development time is much shorter than for a population model. Also, the cohort model provides insight into the income consequences over the entire lifetime of individual persons. This is considered important in assessing behavioural effects of policy measures. The sample of individuals aged 0 in this particular case is a sample of people of different ages entering the disability benefit (the age of their benefit is 0 ). However, when using a cohort model the size and composition of the cohorts should not fluctuate too much over time.

When using a cohort model, by accumulating the first and the second year of the cohort we obtain an estimation of the cost of the new system in the second year. In the same manner, we can deduct the cost of the third year, the fourth year and so on, till an estimation of the structural situation is reached. In fact, as Gilbert and Troitzsch (1999) show, a cohort model can be used to obtain a proxy of the results of a population model. However, when accumulating cohorts this way, the representativity of the cohort is of major importance. Broadly speaking, disability cohorts do not change too much over time as compared to, for example, unemployment cohorts, but the effects of demographic changes, like ageing and changes in participation levels of e.g. women and older people, are missing. Moreover, when making forecasts for the whole population (both the old and the new cases) a sample from the current population should be simulated in any way in order to estimate the total number of disability benefits.

A population model, even though requiring a larger development time, being more time-consuming and generating larger databases, is needed to derive integral forecasts of a complex system change like the one described above. Particularly, the short-term effects of the new measures can be calculated directly and more accurately as compared to a cohort model. In a cohort model these short-term effects have to be deducted, first by accumulating the cohorts for every different cohort simulation and second by adding up the results of the different accumulated cohorts. Also the database of a population model ends up with a large number of cohorts, each of which can be analysed separately so that the typical 'winners and losers'-analysis can be executed. All in all, the dynamic population model appears to fit the case of the disability benefits the best.

\subsection{Model structure}

The model was built using the SAS programming language and consists of four modules. In the first module the base data set is transformed into a consistent set of data. A 
number of records with missing or false data on gender, age and grade of disability are omitted and age-classes (10 years) are constructed. Afterwards, a sample from the current population is drawn and another sample from the cohort of new benefits is added for each year of the simulation, with corrections for demographic developments.

The sample generated in the first module is used in the second module in which the base data are enriched with imputed data on personal income, household type, working status, working history and availability of employer's supplements, so that each person in the sample has a set of 8 characteristics ( 3 basic and 5 imputed) necessary to compute the appropriate benefit level.

The actual simulation takes place in the third module. In this module, a double simulation takes place: one in which the current system of disability benefits is simulated, and one in which the new system is simulated. Both simulations take place with exactly the same sample but with a different set of accounting rules. Finally, the fourth module aggregates the data from the two databases in order to provide various summary output tables on number of benefits, cost of benefits and average benefit height for each forecast year and for every kind of benefit by gender and working status. Scatter graphs in order to judge income mutations on individual level are constructed from the original non-aggregated database.

Figure 2: Summary of modules

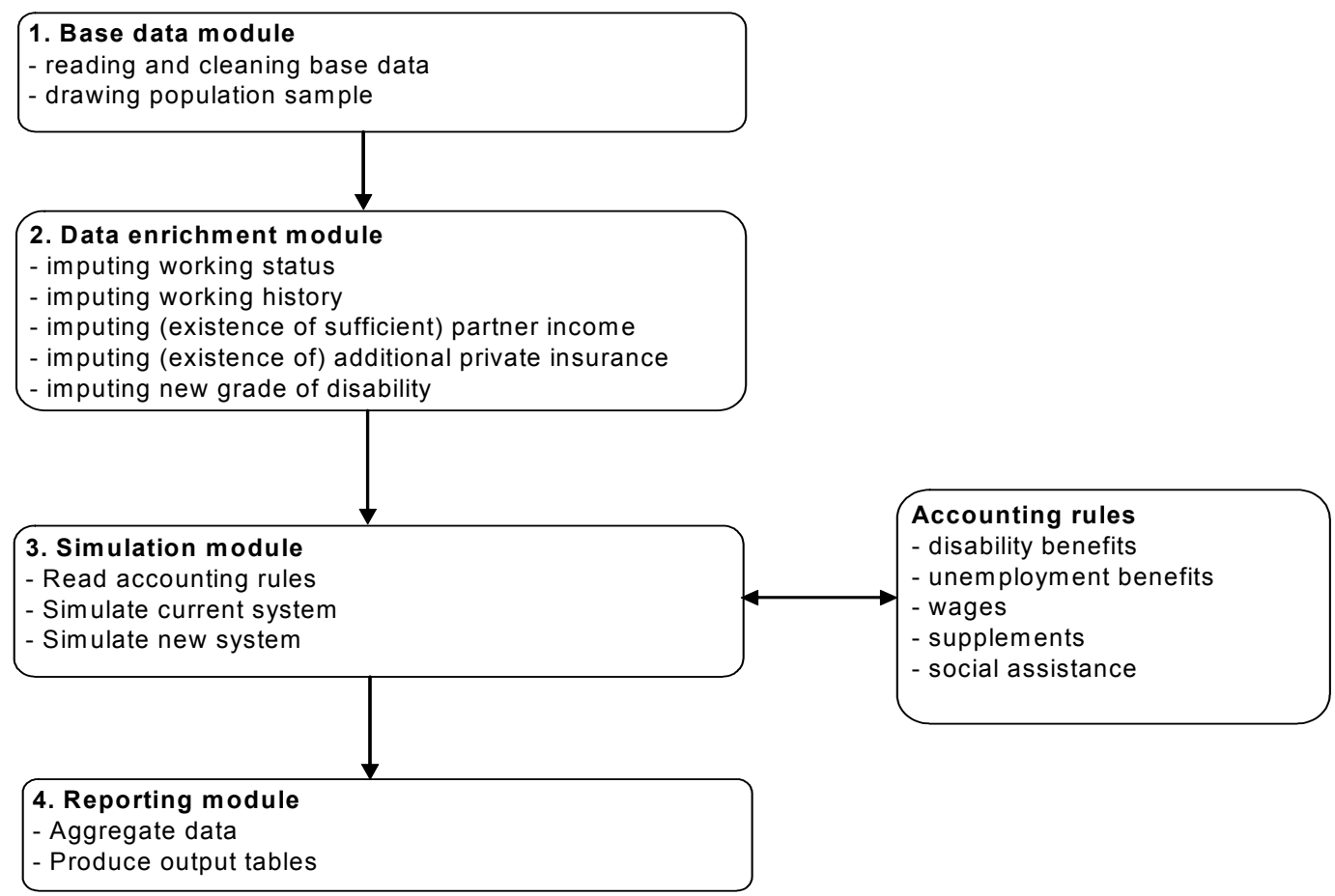

\section{Implementation of the simulation model}

\subsection{The base-data set}

The base data sets consist of records of all 66,635 new disability benefits from 2003 and all 785,595 disability benefits that were being supplied at the end of 2003 . Thus, a full administrative data source has been available for microsimulation. The data sets are supplied by the Central Benefit Administration Office (UWV) about 6 months after year end. Cross 
tables from these data sets were published in UWV (2004). The records contain basic characteristics like age, gender, grade of disability, household type and income. In the basedata module these two datasets are transformed into consistent datasets. Records with incorrect ages (younger than 18 or older than 64), missing grade of disability, missing household type and missing or suspiciously low wages (less than $€ 5$ a day) are removed. As a result of this $16 \%$ of the new benefit records and $8 \%$ of all benefit records are removed, leaving datasets of 56,184 benefits that started in 2003 and 722,646 that existed by the end of $2003^{9}$. On all characteristics, the distribution appears to be highly comparable with the distribution of the full dataset, so the removed records do not cause relevant biases.

Table 2 gives the basic characteristics of the 2003 cohort of new and existing disability benefits.

Table 2: Population characteristics (2003)

\begin{tabular}{|c|c|c|c|c|}
\hline & $\begin{array}{r}\text { New } \\
\text { benefits }\end{array}$ & & $\begin{array}{r}\text { All } \\
\text { benefits }\end{array}$ & \\
\hline \multicolumn{5}{|l|}{ Gender } \\
\hline $\begin{array}{ll}- & \text { male } \\
\text { - } & \text { female }\end{array}$ & $\begin{array}{l}28,645 \\
27,539\end{array}$ & $\begin{array}{l}51 \% \\
49 \%\end{array}$ & $\begin{array}{l}410,123 \\
312,523\end{array}$ & $\begin{array}{l}57 \% \\
43 \%\end{array}$ \\
\hline \multicolumn{5}{|l|}{ Age (2003) } \\
\hline 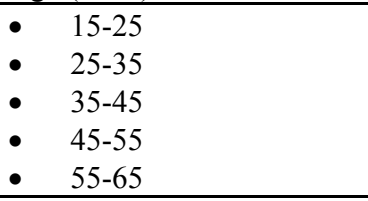 & $\begin{array}{r}1,899 \\
10,715 \\
15,370 \\
17,712 \\
10,488\end{array}$ & $\begin{array}{r}3 \% \\
19 \% \\
27 \% \\
32 \% \\
19 \%\end{array}$ & $\begin{array}{r}4,025 \\
53,828 \\
126,427 \\
220,010 \\
318,356\end{array}$ & $\begin{array}{r}1 \% \\
7 \% \\
18 \% \\
30 \% \\
44 \%\end{array}$ \\
\hline \multicolumn{5}{|l|}{ Grade of disability } \\
\hline $\begin{array}{ll}\text { - } & 15-25 \% \\
\text { - } & 25-35 \% \\
\text { - } & 35-45 \% \\
\text { - } & 45-55 \% \\
\text { - } & 55-65 \% \\
\text { - } & 65-80 \% \\
\text { - } & 80-100 \% \\
\end{array}$ & $\begin{array}{r}5,840 \\
5,369 \\
4,069 \\
4,150 \\
2,223 \\
2,179 \\
32,354\end{array}$ & $\begin{array}{r}10 \% \\
10 \% \\
7 \% \\
7 \% \\
4 \% \\
4 \% \\
58 \%\end{array}$ & $\begin{array}{r}53,431 \\
57,729 \\
46,283 \\
45,050 \\
22,558 \\
22,247 \\
475,348\end{array}$ & $\begin{array}{r}7 \% \\
8 \% \\
6 \% \\
6 \% \\
3 \% \\
3 \% \\
66 \%\end{array}$ \\
\hline \multicolumn{5}{|l|}{ Household type } \\
\hline $\begin{array}{ll}- & \text { singles } \\
\text { - } & \text { couples } \\
\end{array}$ & $\begin{array}{l}14,720 \\
41,464 \\
\end{array}$ & $\begin{array}{l}26 \% \\
74 \% \\
\end{array}$ & $\begin{array}{l}170,951 \\
551,695\end{array}$ & $\begin{array}{l}24 \% \\
76 \% \\
\end{array}$ \\
\hline \multicolumn{5}{|l|}{ Previous earnings } \\
\hline $\begin{array}{ll}\text { - } & <€ 16,391 \text { (minimum) } \\
\text { - } & € 16,391-€ 43,770 \\
\text { - } & >€ 43,770 \text { (maximum) }\end{array}$ & $\begin{array}{r}12,284 \\
41,168 \\
2,732 \\
\end{array}$ & $\begin{array}{r}22 \% \\
73 \% \\
5 \% \\
\end{array}$ & $\begin{array}{r}113,924 \\
579,273 \\
29,449 \\
\end{array}$ & $\begin{array}{r}16 \% \\
80 \% \\
4 \%\end{array}$ \\
\hline Total & 56,184 & $100 \%$ & 722,646 & $100 \%$ \\
\hline
\end{tabular}

The table shows that, even though men outnumber women in the working population, women have a higher chance of getting a disability benefit than men as the shares of inflow of men and women are almost equal. Also, the chance of disability rises with the age. The majority of disability benefits are full benefits (with a grade of disability of $80-100 \%$ ) and the proportion of low incomes (below the minimum wage for full-time employed) is considerable. The latter is caused by both the large number of part-time workers (mostly women) in the Netherlands and the higher chance of obtaining disability benefits that women tend to have.

Using samples instead of whole cohorts adds to the uncertainty of the results. This uncertainty can only be reduced by increasing the sample size. However, simulating the entire cohort (or a very large sample) is impractical because of time- and capacity-constraints. Therefore, a balance between a workable sample-size and a sufficiently low level of randomness has to be found. The randomness due to the sample size is one of various sources

\footnotetext{
${ }^{9}$ The large number of removals is mainly due to missing wages.
} 
of randomness that can be distinguished in microsimulation (Spielauer, 2002). Imperfection randomness applies to both micro- and macro-models, whereas Monte-Carlo variability is inherent in microsimulation.

In order to test for an adequate sample size, for 4 different sample sizes 7 simulation runs each were performed. Then, for two key simulation results (the number of disability benefits in 2040 and the total cost of disability benefits in 2040) the standard deviation of those 7 runs was computed. The results are presented in table 3 .

Table 3: Convergence test

\begin{tabular}{|l|c|c|}
\hline Sample size & $\begin{array}{c}\text { Standard deviation } \\
\text { (absolute / \% of mean) } \\
\text { disability benefit expenses 2040 }\end{array}$ & $\begin{array}{c}\text { Standard deviation } \\
\text { (absolute / \% of mean) } \\
\text { number of benefits 2040 }\end{array}$ \\
\hline $1 \%$ & $€ 90 \mathrm{mln} / 1.0 \%$ & $9,000 / 1.1 \%$ \\
\hline $2 \%$ & $€ 80 \mathrm{mln} / 0.9 \%$ & $7,000 / 0.8 \%$ \\
\hline $5 \%$ & $€ 40 \mathrm{mln} / 0.4 \%$ & $4,000 / 0.5 \%$ \\
\hline $10 \%$ & $€ 40 \mathrm{mln} / 0.4 \%$ & $3,000 / 0.4 \%$ \\
\hline
\end{tabular}

Of course, larger samples produce more accurate results, but also complicate quick data analysis of the simulation data. The analysis shows that a sample size of $5 \%$ leads to small enough standard deviations of less than $0.5 \%$ of the mean. In absolute terms a $5 \%$ sample leads to a standard deviation in total expenses of $€ 30 \mathrm{mln}$ (so a $95 \%$ chance of deviating less than $€ 60 \mathrm{mln}$ from the mean) and a standard deviation in total number of disability benefits of 4,000 (so a $95 \%$ chance of deviating less than 8,000 from the mean). Doubling the sample size to $10 \%$ does not add much in terms of the accuracy of results concerning the whole population. Nevertheless, in order to secure more accurate analyses on smaller subgroups, a $10 \%$ sample is used.

Therefore, a 10\% sample from the disability benefit population of 2003 is drawn. For all years in the simulation (2004-2040) a 10\% sample from the new benefits is drawn with an adjustment for the expected demographic changes. The adjustments are based on projections of the inflow from 2004-2040 as made by the UWV for a report by the Social-Economic Council (see also SER, 2004). The UWV-projections are based on recent forecasts of the workforce by the Netherlands Bureau of Economic Policy Analysis (CPB, 2004) in which the labour participation of especially women and older workers rises ${ }^{10}$.

The accumulation of a $10 \%$ sample of the existing benefits and 37 cohorts of new benefits amounts to a base dataset of almost 400,000 records.

\subsection{Imputation of missing data}

Other important characteristics like working status (after disability), working history (before disability), availability of a supplement to the second phase disability benefit and partner income (which determines entitlement to and the level of social assistance) are not included in the base data set. Nevertheless, these data are known at aggregate level from other public data sources of similar populations. Therefore, these characteristics are imputed using a technique similar to the 'random hot-deck method', in which values are randomly imputed using a known distribution of these values.

Working status is known from the whole population of disability benefits in 2002 for subgroups of gender, age-class and grade of disability (see table 4). Working history is known

\footnotetext{
${ }^{10} \mathrm{CPB}$ presents four scenarios varying from a global economy, in which the labour force grows the most, to the opposite in which the labour force shrinks. The Global Economy scenario was also used in earlier publications by CPB and SER. In paragraph 3.5 we will discuss the labour market scenarios in more detail.
} 
from a sample of the cohort of new disability benefits in 1999 for subgroups of gender, ageclass and grade of disability. Availability of a supplement to the second phase disability benefit (through private insurance paid for by employers and employees together) is known only as a general percentage ( $80 \%$ ) of the whole working population from a survey among a panel of employers (van Deursen et.al.,1997). For couples, the existence of a second income is imputed using overall averages for men and women. These averages are based on a sample of new benefits in 1999. This sample of new benefits is followed in time by UWV concerning an epidemiological survey (called EPI) among people who receive a disability benefit.

Table 4: Imputation scheme

\begin{tabular}{|l|l|l|l|l|l|} 
& \multicolumn{3}{|c|}{ Gender } & Distribution \\
\hline Working status & X & X & X & All benefits 2002 (UWV) \\
\hline Working history & X & X & X & Sample of new benefits 1999 (UWV) & $(0,1)$ \\
\hline Partner income (existence) & X & & & Sample of new benefits 1999 (EPI) & $(0,1)$ \\
\hline $\begin{array}{l}\text { Supplement second phase } \\
\text { disability benefit }\end{array}$ & & & & Research report 1997 (ZARA) & $(0,1)$ \\
\hline
\end{tabular}

\subsection{The simulation module}

In the simulation module, in order to measure structural effects, theoretically, the simulation should run until all old cases are replaced by new cases. In the case of disability benefits this would mean a simulation duration of 47 years as the minimum age that entitles to a disability benefit is 18 and the maximum age is 65 . However, the number of younger people receiving a disability benefit is comparatively low. In 2040, less than $1 \%$ of the starting population is still receiving a disability benefit. Therefore, we fix a simulation duration of 37 years, starting 2004 and ending 2040.

The simulation starts at the entry examination by imputing, for every person in the sample, the grade of disability after the implementation of the new eligibility criteria given a grade of disability before the implementation of the new criteria. The new criteria decreases the chance of being allowed a full disability benefit and also raises the chance of being included in a lower class of disability than would be the case at the moment. The new grade of disability is imputed using a transformation matrix, supplied by UWV, which describes the chance that, if the grade of disability equals (i), the grade of disability according to the new criteria will equal (j). This transformation matrix was itself the result of a computer simulation by UWV of the effects of the new criteria on a sample of new benefits in $2002^{11}$.

The simulation loop consists of a set of deterministic functions that determine the various benefit levels, and of a set of stochastic functions that determine the progress and the set of parameters to be used the next year. For each case in the sample, total personal income from various sources is determined for the first year of disability.

The simulation then continues on to the next year. Firstly, the occurrence of major events (recovery from disability, retirement or death) is simulated. Individuals can quit the simulation in case of death, recovery from disability or retirement. Chances of death and recovery from disability are determined using group averages based on age, gender and grade of disability. Occurrence of these events is determined by a Monte Carlo process. A person becoming 65 years of age quits the simulation automatically. If a person keeps a benefit for the new year, using the same method, a possible change in the grade of disability and in the working status is simulated. Secondly, with the actualised set of parameters, the new benefit heights are determined for the second year. In the end, a simulation data set appears,

\footnotetext{
${ }^{11}$ Transformation matrix available upon request.
} 
consisting of all cases in the sample, the duration of the simulation and 7 types of income components ( 6 different kinds of benefits plus wage in case a person worked in a certain year). Figure 3 illustrates the simulation process. The deterministic functions determine the different kinds of benefit levels given a set of parameters belonging to person (i) in year ( $t$ ). The stochastic functions determine whether the person continues the simulation for one more year or not.

Figure 3: Simulation loop ${ }^{12}$

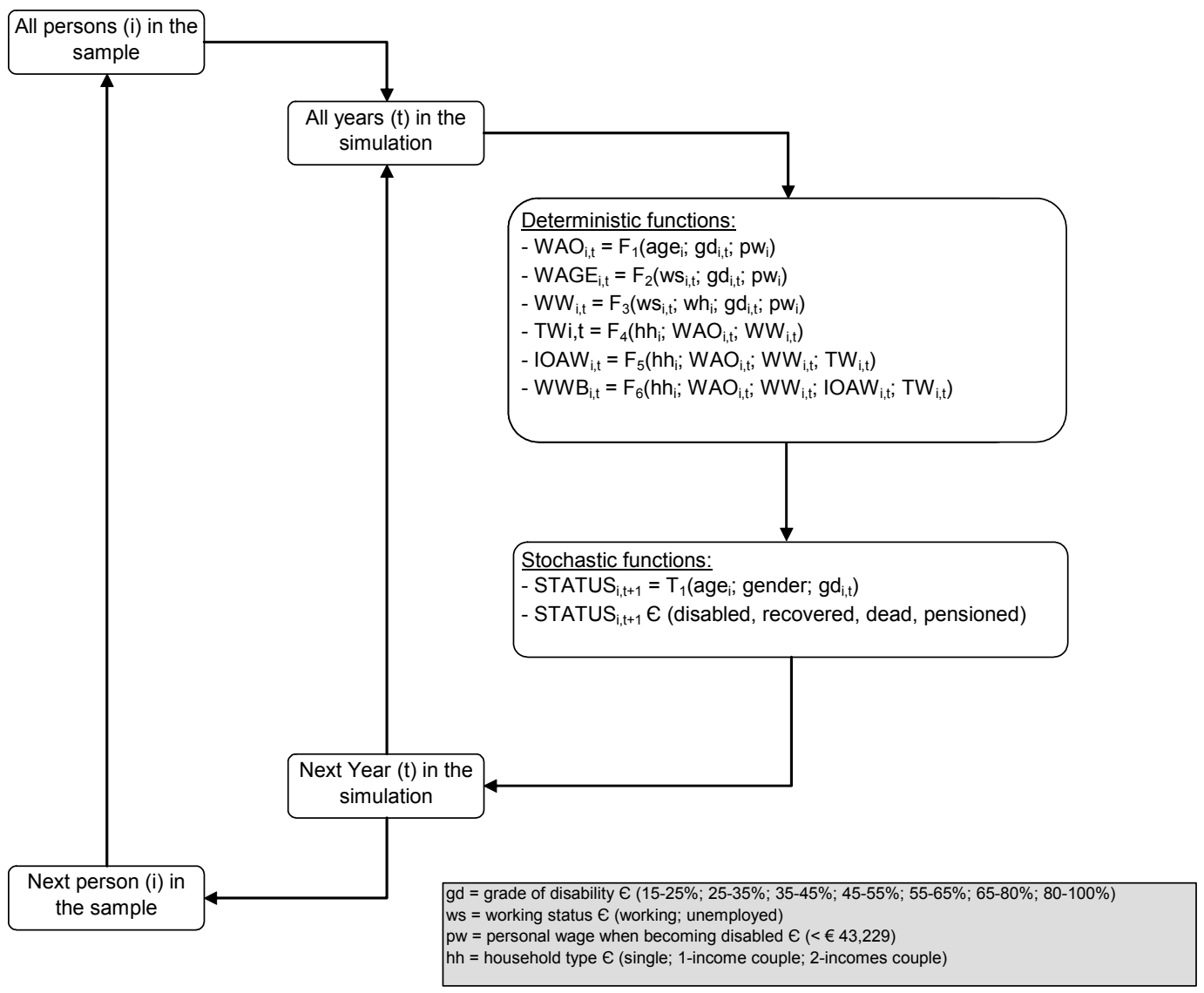

Not all personal characteristics are supposed to be dynamic. For simplicity the household type is supposed to be fixed over time. Fixing household type is not very realistic when looking at the real world where households are in fact dynamic. However, in the case of disability benefits, fixing the household situation is a reasonable assumption because the majority of the cohort is over 40 years of age and changes in household type for this age category are not as frequent as compared to younger populations.

Generally speaking, increasing the dynamics of the model is not always preferable. A dynamic grade of disability and working status is clearly more realistic. For example, individuals suffering from a progressive disease, will have an increasing grade of disability over time, whereas individuals recovering from a disease, will sometimes have a slow decreasing grade of disability over time. The working status of these individuals will be affected by the changing grade of disability as well. In reality, people do not always work for a consecutive period of many years, but may get hired for shorter periods of time or get fired after a while. Introducing dynamics in grade of disability and working status makes it difficult when one wants to identify large homogeneous groups. Instead of major groups like the

\footnotetext{
${ }^{12}$ See Appendix for a more detailed description of benefits.
} 
working partially disabled and the unemployed partially disabled, one ends up with a large inbetween group of people who work part of the time and are unemployed at other times. Depending on the extra value of these dynamics for the macro results and the problems in identifying homogeneous groups, one can choose for a simulation with or without dynamics in these characteristics.

\subsection{The behavioural model}

Besides the dynamics described in paragraph 3.3, microsimulation also involves modelling the behaviour of individuals, taking into account the effects of policy parameters such as tax rates, eligibility rules for benefits and subsidies and compensation rates in the social security system (Klevmarken, 2001).

Behavioural effects as a result of financial triggers are included in the simulation module. To measure these behavioural effects of the system change on the labour participation, two additional important assumptions are built into the model. First, the financial incentives, which are calculated using the conventional methods using an income elasticity (see paragraph 1.3) on the change in replacement rate, are considered not to influence the number of new benefits but only the participation status of those benefits ${ }^{13}$. If working is made more attractive for the partially disabled, the total number of new benefits is assumed not to change, but the share of labour participants in this total is assumed to rise. Second, if someone gets a lower disability grade because of stricter allowance criteria, the probability that someone participates on the labour market changes to the level belonging to that new disability grade. This assumption reflects the viewpoint that the partial disability benefit is an instrument of reintegration in itself (e.g. de Jong \& Thio, 2002 and Besseling, 2002).

In our model we abstract from the effects of eligibility rules. Possible effects of eligibility rules are diverse but hard to model. Part of the system change is that so called soft diagnosis claims (disabilities that are based on subjective symptoms like chronic fatigue syndrome and whiplash) will be examined more vigorously. However, data on those soft diagnoses are not very reliable and spillovers can occur from one illness to another, e.g. if whiplash is not eligible and depression still is, workers non-eligible in one category may seek eligibility in another.

For an overview of the behavioural model used, see appendix B.

\subsection{Model validation}

Caldwell and Morrison (2000) find that validation methods for longitudinal dynamic microsimulation models are underdeveloped and underutilized. They address the validation of such models from several perspectives like consistency of simulated results with administrative data, consistency with survey data, comparability with results from other nonmicrosimulation models and special validation challenges posed by the Monte Carlo nature of the microsimulation models. The latter is dealt with in paragraph 3.1. The other validation perspectives we have used in the following way.

First, the distribution of the imputed data is compared to the original distribution as known from separate aggregate data sources. Second, the model output for the base year is compared to the realisations as known from public data sources by UWV. Third, the model results for the forecasting years are tested on plausibility by comparing them both to long-

\footnotetext{
${ }^{13}$ Implicitly. we assume that the medical status of a person is given and the result of an entrance examination cannot be influenced by financial triggers. Of course, since labour participation increases recovery chances, in an indirect way, the number of benefits is still influenced in our model.
} 
A microsimulation analysis of the 2006 regime change in the Dutch disability scheme

term forecasts from other public data-sources and by recognizing expected trends not yet quantified. Examples of such trends are the following:

1) A drop in average disability benefit level as people who entered the disability benefit since 1993 qualify for a higher first phase benefit followed by a lower second phase benefit, whereas people who entered the disability benefit before 1993 (who now slowly phase out because of pensioning) keep the higher first phase benefit until they turn 65.

2) A rise in use of social assistance, because the average benefit height drops and more low part-time incomes entered the disability benefit in recent years.

3) A drop in partial unemployment benefit because the duration of the unemployment benefit is decreased by 2 years as a consequence of a policy measure from 2003.

All these trends were recognised in the model output. Also, two interesting deviations appeared:

1) The numbers of unemployment benefits are predicted to be $20 \%$ higher than known from micro data analysis. This can be attributed to so-called voluntary unemployment. People make a trade-off between the level of the unemployment benefit and the requirements that come with it, like being obliged to be available to the labour market.

2) The numbers of social assistance benefits are predicted to be far higher than known from realisations whereas the average level of the social assistance is far lower than known from the same data sources. Apparently, if the social assistance someone is entitled to is too low, people do not bother to get it because social assistance also has strict requirements on availability to the labour market and strict wealth information requirements. Because of this model validation result, the model is adapted so that social assistance lower than a certain threshold value, is assumed not to be used. The threshold value is set at a value that produced average benefit levels equal to the ones known from other data analysis.

\subsection{Sensitivity analysis}

The simulation we use in the budget forecasts is a base scenario with some important assumptions concerning the development of the labour force, the income elasticity and the discounting rate. In order to test for the sensitivity of the simulation results we perform a sensitivity analysis using different assumptions.

First, the development of the labour force is based on one of the four scenarios for the Netherlands by the Netherlands Bureau of Economic Policy Analysis (CPB, 2004), called Global Economy. This scenario has the strongest growth of the labour force. The scenario assumes a continuing economic growth and a strong rise in labour participation among the elder working force and among women. This scenario assumes successful international cooperation and a strong focus on individual responsibilities. An alternative scenario, called Regional Communities, is one in which economic growth stagnates and the labour force shrinks compared to the current level. This scenario assumes national sovereignty instead of international cooperation and a strong role for the public sector. All four scenarios contain underlying assumptions about the development of the disability benefit law, so use of the scenario data in order to make projections of the number of disability cases should be done with care. The Global Economy scenario was previously used in partial macro computations of the system change (SER, 2004) and assumes a strict disability benefit system with a decreasing number of disability benefits. Replacing Global Economy with another scenario and assuming no change in the disability system reduces the expected number of disability cases in both the old and the new system and, as a consequence, the savings of the new 
system. Indicative data, using the Global Economy scenario as a base scenario with an index of $100 \%$, are presented in the following table.

Table 5: Sensitivity analysis on labour market scenarios (in 2040)

\begin{tabular}{|c|c|c|c|c|}
\hline Labour market scenario & $\begin{array}{l}\text { Labour force } \\
\text { (x } 1 \text { million) }\end{array}$ & $\begin{array}{r}\text { Disability } \\
\text { benefits without } \\
\text { system change }\end{array}$ & $\begin{array}{r}\text { Disability } \\
\text { benefits with } \\
\text { system change }\end{array}$ & $\begin{array}{r}\text { Savings of } \\
\text { system change }\end{array}$ \\
\hline Global Economy (base scenario) & $9,0(100 \%)$ & $100 \%$ & $100 \%$ & $100 \%$ \\
\hline Transatlantic Market & $7,9(88 \%)$ & $90 \%$ & $92 \%$ & $81 \%$ \\
\hline Strong Europe & $7,6(84 \%)$ & $89 \%$ & $90 \%$ & $85 \%$ \\
\hline Regional Communities & $6,6(73 \%)$ & $79 \%$ & $79 \%$ & $76 \%$ \\
\hline
\end{tabular}

The table shows that in the Regional Communities scenario, the other extreme, the labour force is 27\% smaller than in the Global Economy base scenario in 2040 (see table 5, $73 \%$ compared to $100 \%$ ). The number of disability benefits in the simulations of both the current and the new system are $21 \%$ smaller. As a consequence, the savings of the system change in the Regional Communities scenario decreases by more or less a similar amount (about 24\%). However, one key assumption in this scenario is a strong public sector and an extensive system of social security excluding the stricter disability measures currently being proposed. Therefore, the number of disability benefits in this scenario will rise again and thus surpass the current level in table 5.

Second, in our sensitivity analysis we assume that the income elasticity is 1.5 , based on a Canadian study (Gruber, 2000), which may not be accurate for the current Dutch situation. However, there is not just one accepted theory or only one generally accepted value for an elasticity (Nelissen, 1991, 1993). Recent results of a study done by the CPB (CPB, 2005) based on Dutch data from 1996-2000, suggest the elasticity to be at least 2.5. Therefore an alternative scenario with an elasticity of 3.0 is tested. However, the level of the elasticity may well be dependent on the strictness of the entrance examinations. If entrance criteria are loose, medical reasons are less important and financial considerations can play a more significant role. At the moment, entrance criteria are implemented rather strictly. Therefore, an alternative scenario with a lower elasticity of 0.75 is also tested.

Table 6: Sensitivity analysis on income elasticity (2040)

\begin{tabular}{|l|r|r|}
\hline Income elasticity & $\begin{array}{r}\text { Number of working } \\
\text { disabled after system } \\
\text { change }\end{array}$ & $\begin{array}{r}\text { Total cost of benefits } \\
\text { after system change }\end{array}$ \\
\hline 1.5 (base scenario) & $100 \%$ & $100 \%$ \\
\hline 0.75 & $95 \%$ & $102 \%$ \\
\hline 3.0 & $119 \%$ & $95 \%$ \\
\hline
\end{tabular}

Using an income elasticity of 3.0 increases the financial incentive to work. As a consequence, the number of disabled that are working increases by $19 \%$ and the total cost of benefits are reduced by $5 \%$ (see table $6,95 \%$ compared to $100 \%$ ). By using an elasticity of 0.75 the opposite happens, the number of working disabled is reduced by $5 \%$ and the total cost of benefits increases by $2 \%$.

Third, the real discounting rate is set at $10 \%$ based on estimates used in earlier studies by the CPB. In these studies the real discount rate is a function of the expected nominal interest rate, inflation, life expectancy and an uncertainty factor. The discounting rate influences the behavioural effects in the following way. A lower discounting rate increases the weight of income changes in later years. As the financial incentives of the new disability regime are most visible in later years, using a lower discounting rate would increase the 
changes in replacement rate and increase the labour participation of the partially disabled further. We test an alternative scenario with a discounting rate of $5 \%$. This only implies minor changes in the replacement rates.

The financial incentives are aimed especially at the non-working partially disabled. This subgroup will, on average, notice the lower benefit after two years. Assuming an average benefit duration of ten years, using a discounting rate of $5 \%$ instead of $10 \%$ reduces the weight of the first two years in the total income by 5 percentage points and increases the weight of the later years by 5 percentage points. This change for only one subgroup appears to be too small to substantially influence the main results ${ }^{14}$.

\section{Results of the simulation model}

In this chapter we examine the forecast results of the simulation model in order to determine the effects of the new system of disability benefits, as proposed to the Dutch Parliament (Tweede Kamer der Staten-Generaal, 2005). The baseline is the structural situation of the current system, which is the system as it was before the tightening of the eligibility criteria that has been in force from October 1, 2004. Paragraph 4.1 deals with the macro results and paragraph 4.2 deals with the micro results.

\subsection{Macro results}

Like most other developed countries, the Netherlands is faced with an increasing share of elderly persons that have a higher chance of getting disability benefits. The current system leads to about 750,000 disability benefits in 2040 , costing $€ 9,9$ billion. In order to simulate the new system, the changes in the rules are categorised and simulated both separately and simultaneously. The main changes in the new system are the following:

1) Stricter allowance criteria that decrease the chance of being allowed a full disability benefit and also raise the chance of being included in a lower class of disability than would be the case at the moment. Because of the stricter allowance criteria, more jobs will be found at the entrance examination. This implies that jobs are found in cases where in the current system, not enough jobs would have been found. If a job earns enough compared to the former wage, the entitlement to a disability benefit can end.

2) Exclusion of the lower two classes of disability (15-25\% and $25-35 \%)$;

3) Changes in the benefit regime:

a. A less attractive benefit regime for partially disabled that are unemployed (their income is limited to a share of the social minimum equal to the grade of disability);

b. A more attractive benefit regime for partially disabled that are working (they keep their higher first phase disability benefit as long as they work);

c. A more attractive benefit regime for the fully disabled (they keep their higher first phase disability benefit as long as they are fully disabled);

d. Extension of the duration of the higher first phase disability benefit by on average 1 year.

These changes can be simulated both separately and simultaneously. The stricter allowance criteria have been in force from October 1, 2004. The exclusion of the lower two

\footnotetext{
${ }^{14}$ The use of a very high discounting rate would, of course, influence the results. For example, in a theoretical scenario with a discounting rate of $100 \%$, the financial incentives would disappear altogether. In such a scenario, only the benefit change in the first year would influence the replacement rate.
} 
classes of disability and the changes in the benefit regime are proposed to be in force from January 1, 2006. Sometimes the combined effect of two policy changes is greater than their separate effects. For example, because of the stricter allowance criteria, more people populate the lower two classes of disability, so exclusion of these two lower classes has a larger effect. Sometimes the opposite is true as well. For example, when a lower benefit level is considered, the effects will decrease when stricter allowance criteria yield fewer benefits.

The new system leads to about 550,000 disability benefits in 2040 , costing $€ 8,0$ billion. As mentioned earlier, the old system leads to about 750,000 disability benefits costing $€ 9,9$ billion. The number of disability benefits is reduced by $27 \%$ and the total cost of all social security benefits (including supplementary benefits from private insurance companies) by $19 \%$. The amount of income from wages of working disabled people rises from $€ 2,1$ billion in the old system to $€ 3,8$ billion in the new system. The projected development of the number of disability benefits is shown in figure $4^{15}$.

Figure 4: Number of disability benefits before and after system change

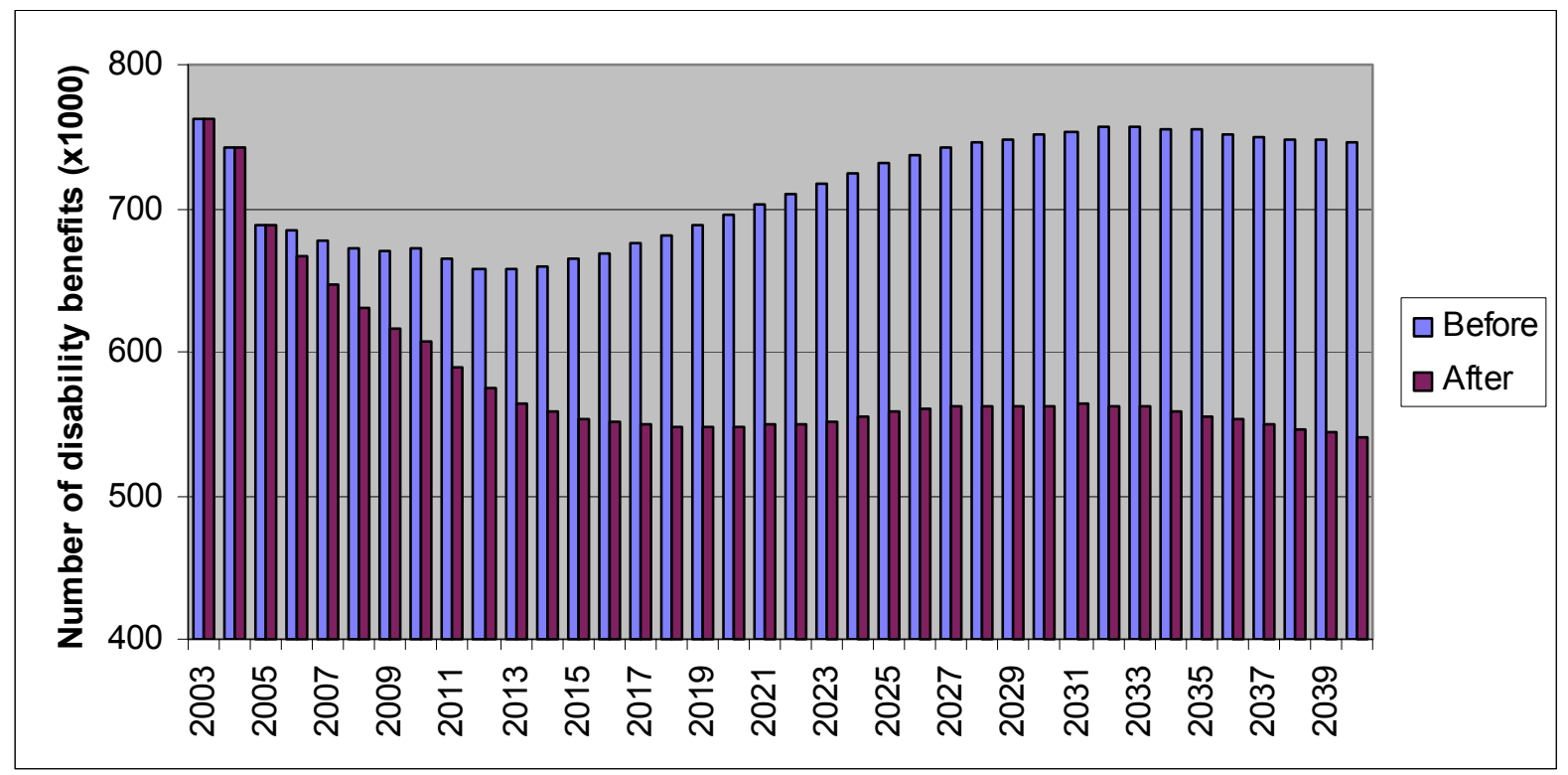

The new system leads to a steady reduction in numbers of benefits as compared to the old system (see figure 4). Roughly, three stages can be distinguished for the old system:

1) From 2006-2015, the number of benefits drops slightly, mainly due to a high number of pensioners from 2010 onwards.

2) From 2015-2030, the number of benefits grow rapidly to the maximum level of over 750,000 . One obvious cause of this rise is the growth of the workforce but more significant than its growth is the composition of the workforce. The share of older people and women in the workforce rises and both the older and the women have a higher than average disability risk.

3) After 2030, the number starts to fall slightly. The workforce, according to the current projections, starts to fall after 2025 and with some delay this influences the number of disability beneficiaries in later years.

\footnotetext{
${ }^{15}$ In 2005 , the number of benefits drops sharply by about 50,000. This is caused by the extension in 2004 of the duration of sickness benefit from one to two years. Sick employees stay with their employers for 2 years, before they can enter the disability benefit scheme.
} 
The fall in number of disability benefits is a gross effect of the system change. The net effects of the system change are more important. Both direct and indirect effects play an important role here. Direct effects assume a steady state situation in which the behaviour of people does not change. For example, someone who gets a disability benefit in the current system can get no disability benefit in the new system because of the stricter allowance criteria. A direct effect of such a change can be that the person considered will get an unemployment benefit or social assistance instead. So, when direct effects are calculated the net effect of the system change will be smaller than the gross effect.

Moreover, when behavioural effects are taken into account, the effects can increase. Using the same example, taking into account that the unemployment benefit or social assistance are less attractive than the disability benefit, the person considered can decide to work instead of receiving a benefit. Because of such behavioural effects, a rise in the working population is to be expected. This is exactly the intention of the new disability law. Following the assumptions described in paragraph 3.3, the working population increases by more than 80,000 (see figure 5), and the total wages earned increases by $€ 1,7 \mathrm{bln}$.

Figure 5: Number of people working before and after system change among the group that qualifies for the disability benefit before the system change

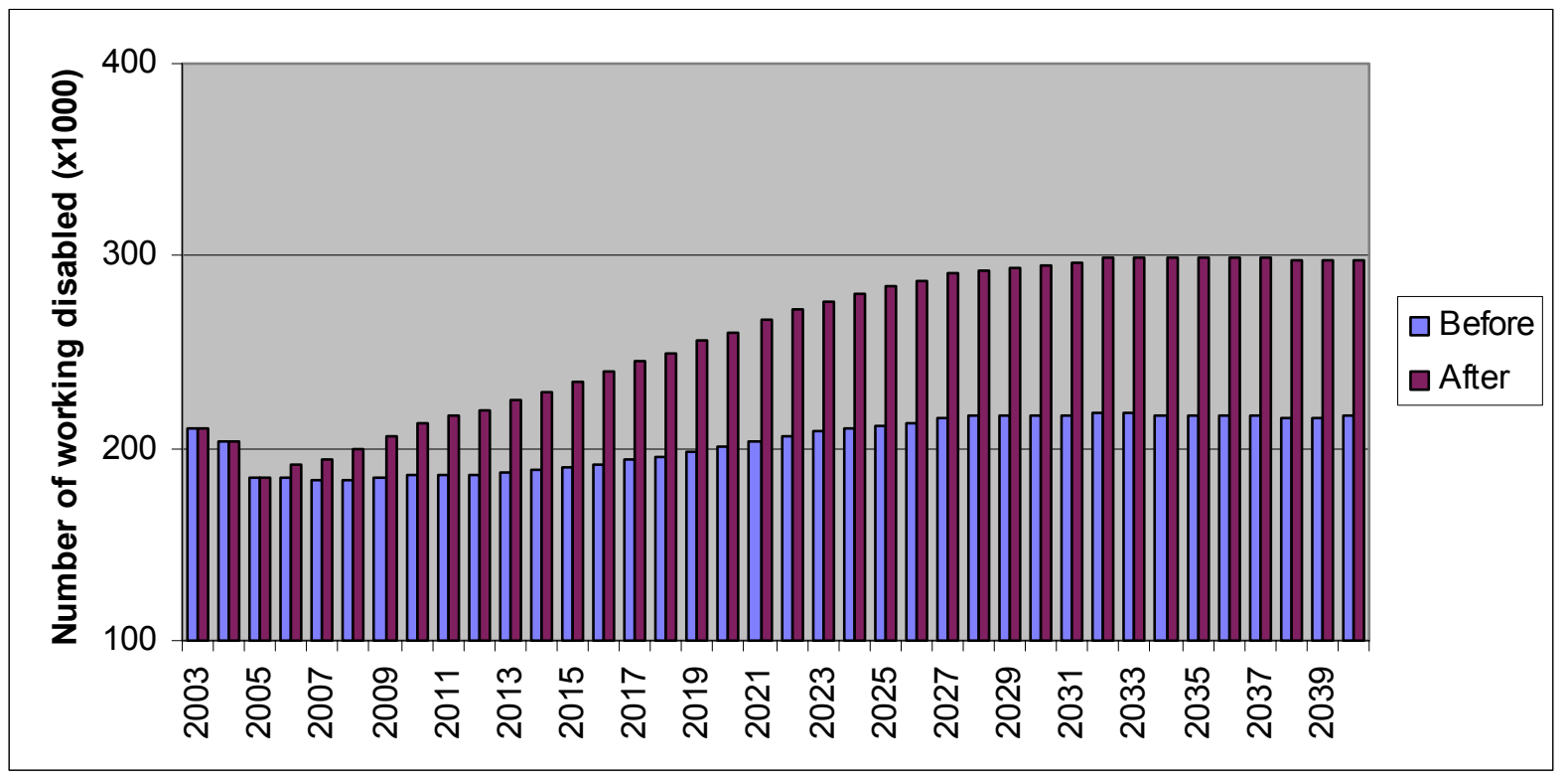

Direct effects of the system change account for $70 \%$ of the total savings. The stricter allowance criteria are the most important here, whereas the changes in the benefit regime actually induce extra costs when only direct effects are taken into account. Behavioural effects account for $30 \%$ of the total savings. Here, however, the changes in the benefit regime do play an important role in the savings because the new system increases the difference between the benefits for the working partially disabled and the unemployed partially disabled, which makes working more attractive.

Finally, figure 6 shows the development of the total cost of benefits for the disabled. This includes disability benefits, unemployment benefits, social assistance and supplementary benefits from private insurance companies. The total cost of the new system as compared to the old system is reduced by $19 \%$ or $€ 1,9$ billion in 2040 .

The savings of the system change are slightly smaller than earlier used macro models predicted. This is a common result when comparing micro to macro models. Usually if a policy measure generates savings, the income level below minimum are somehow 
compensated. If so, applying rules to means produces higher estimates than applying rules to individuals, because for part of the individuals the policy measures have no consequences. Of course, if using a macro model, one can take this aspect into account by extending the number of relevant subgroups to include also the groups that will be partially or fully compensated, but this will lead to increasingly complex macro models.

The development in time of the total expenses follows the same pattern as figure 4 (disability benefit expenses). The ageing workforce leads to a $13 \%$ increase in total expenses between 2015 and 2030. After 2030 expenses stabilise. The expenses can be compared to the total insured income of the working population, which at the moment amounts to $€ 175$ billion (2004 estimation). The expenses in figure 6 are net expenses, which should be increased by about $25 \%$ for cost of executing the disability law, cost of reintegration etc. Taking into account the growth of the workforce, the burden of disability benefits then drops by about $1.4 \%$ from $7.1 \%$ to $5.7 \%$.

Figure 6: Total cost of all social security benefits before and after system change for people that would qualify for the disability benefit before the system change

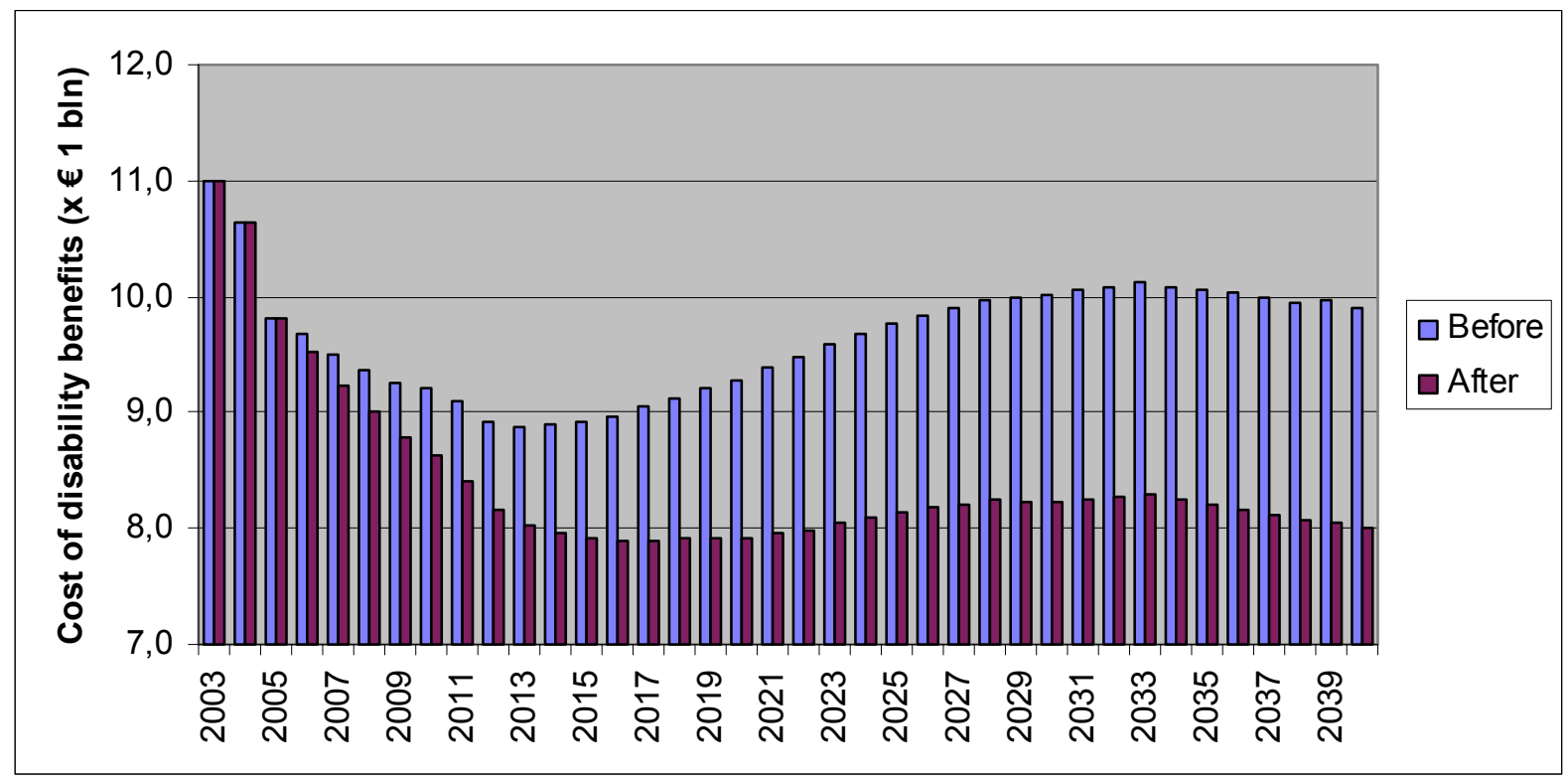

Comparing the microsimulation model results to a macro cohort model used to predict the time path of the savings, the expected savings of the system change in the early years surprisingly appear to have been predicted too high. The net savings as a percentage of the long-term savings after 4 years were predicted to be $29 \%$ with a simple macro model and appeared to be only $21 \%$ in the microsimulation model. Again, the use of means appears to have played an important role. Using average durations of benefits, the new population seemed to replace the old population quite rapidly, whereas using individual recovery chances that depend on the duration of the benefit, the new population appeared to build up more slowly, so that savings come later than expected.

\subsection{Micro results}

The population model indicates the macro-effects of system changes and their development in time. Isolating one or more cohorts (so in fact reducing the population model to a cohort model), an estimation can be given of the direct income effects of the system change for a cohort of new benefits. This indicates the effects on the long-term incomes of 
individuals in order to find the "winners" and "losers" of the system change and the amount they win or lose. Winners in our article are those individuals that improve financially in their situation, without taking loss of leisure into account. Moreover, this is a starting point for further analysis because the projected long-term income effects are expected to cause behavioural effects. For example, if the projected long-term income of an individual falls, this individual will more likely work.

For every person in the simulation, total discounted individual income during the disability period is measured. The real discounting rate is fixed at $10 \%$ a year, based on assumptions used by the $\mathrm{CPB}$ as discussed in paragraph 3.5. The accumulating period is maximised to 20 years, because not much valuable information is gathered from additional years since discounting weights decline. For all people that enter the new benefit system from 2006-2020, total discounted individual incomes are estimated in both the old and the new system. This number, divided by the accumulated discounted income before disability, is the replacement rate. Table 5 gives average long-term replacement rates for the six main subgroups in the system (the grey boxes from figure 1).

Table 7: Replacement rates by subgroup

\begin{tabular}{|c|c|c|c|}
\hline Subgroup & $\begin{array}{l}\text { Replacement } \\
\text { rate old system }\end{array}$ & $\begin{array}{l}\text { Replacement } \\
\text { rate new system }\end{array}$ & $\begin{array}{r}\text { Projected } \\
\text { income } \\
\text { mutation }\end{array}$ \\
\hline Permanently, fully disabled & $72 \%$ & $73 \%$ & $+1 \%$ \\
\hline Temporarily, fully disabled & $73 \%$ & $74 \%$ & $+1 \%$ \\
\hline Partially disabled, working & $82 \%$ & $84 \%$ & $+1 \%$ \\
\hline Partially disabled, unemployed, one-income & $66 \%$ & $62 \%$ & $-4 \%$ \\
\hline Partially disabled, unemployed, second-income & $60 \%$ & $47 \%$ & $-13 \%$ \\
\hline Partially disabled, $<35 \%$ & $77 \%$ & $65 \%$ & $-12 \%$ \\
\hline All disabled & $72 \%$ & $72 \%$ & \\
\hline
\end{tabular}

The development of the replacement rates clearly points out how the incentives of the new system work out. The fully disabled and the partially disabled that are working increase their replacement rate by 1-2 percentage-points whereas the partially disabled who are unemployed have a considerably lower replacement rate. This holds especially for the unemployed with earning partners because they will not get social assistance. These figures show that there is an incentive for partially disabled to work more. This incentive to work, leads to an increase in the number of working disabled and a decrease in the number of unemployed disabled. The average replacement rate for all disabled is therefore stable. This is consistent with the macro results presented earlier, which include a $€ 1,9$ billion drop in benefit costs and a $€ 1,7$ billion rise in wages. ${ }^{16}$

Figure 7 shows the income development of the partially disabled in the new system. The figure shows the total accumulated income for each person in the simulation in the current system (x-axis) and the new system (y-axis) ${ }^{17}$.

\footnotetext{
${ }^{16}$ The replacement rate is stable although the drop in cost of benefits exceeds the rise in wages. This can be explained by the time path of these mutations: apparently the rise in wages on average takes place earlier than the drop in benefits.

${ }^{17}$ A dot on the $\mathrm{x}=\mathrm{y}$-axis means that no income mutation took place, dots to the right of the $\mathrm{x}=\mathrm{y}$-axis point to income decreases and points to the left of the $\mathrm{x}=\mathrm{y}$-axis to income increases.
} 
Figure 7: Income development working partially disabled

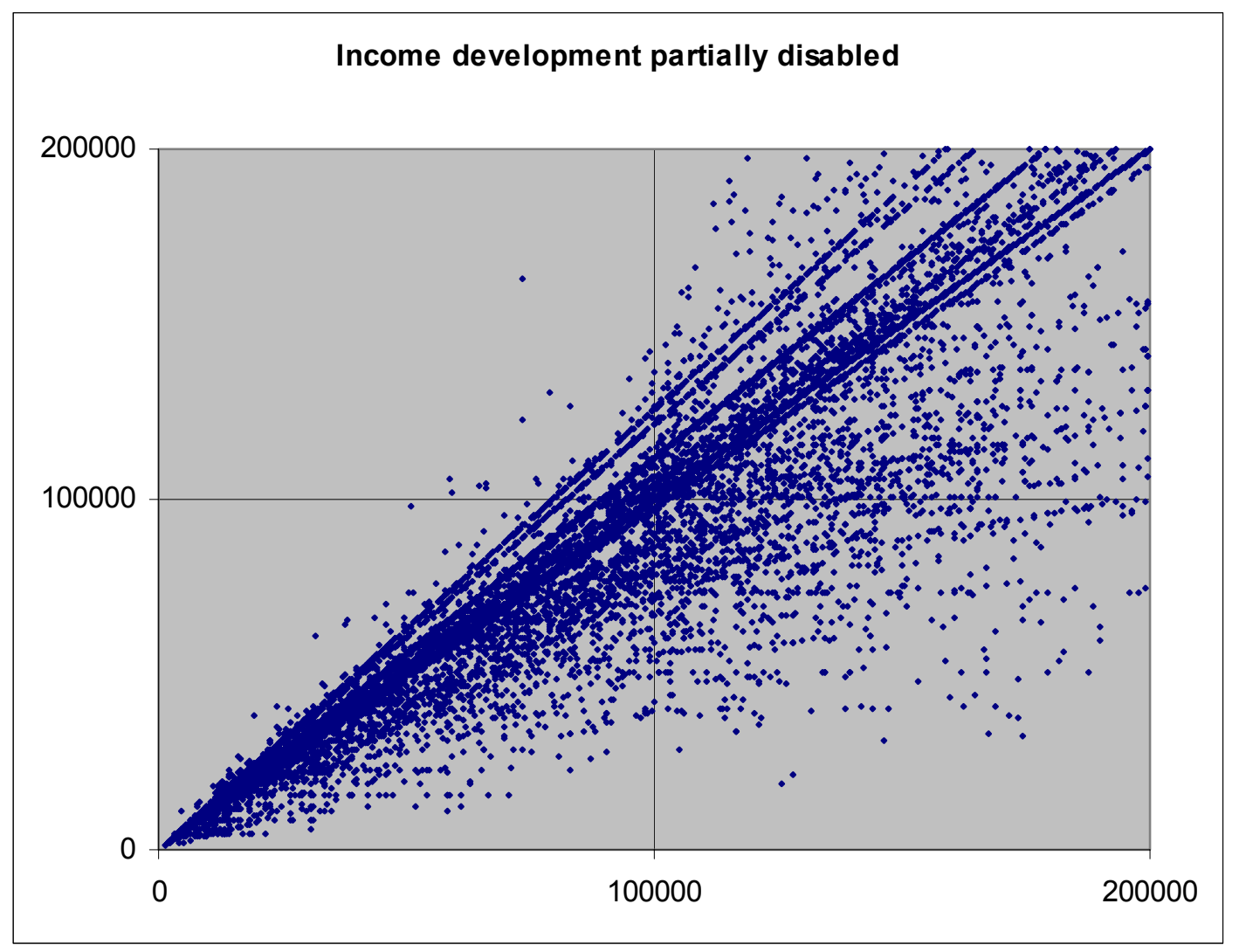

Dots above the $\mathrm{x}=\mathrm{y}$-axis belong to the working partially disabled. The highest income increases are among the partially disabled who would not be working in the current system, but will be working in the new system because of its better incentive structure. But also the partially disabled who would be working now and would do so in the new system as well can belong to the winners of the system change. Every disability benefit is replaced by a lower second phase disability benefit after a while, but for a large majority of employees the difference between both is compensated by collective insurances. However, for the small group that is not compensated now, there will be an income rise in the new system as the lower second phase disability benefit is abolished for the working.

Dots below the $\mathrm{x}=\mathrm{y}$-axis belong to the unemployed partially disabled. Two categories of partially disabled in particular are at risk: the higher incomes and the two-income couples which have a long duration of disability. The steepest falls in individual income occur in these groups. For the partially disabled who are not working, there will be a first phase benefit which is as high as in the current system. During this phase, people have the opportunity to find a job. When first phase benefits end, the second phase benefit equals a share of the social minimum level, corresponding to the grade of disability. High incomes will lose the most; low incomes can often keep their current benefit height. That is, if they are breadwinners or singles. When there is a second income in the household higher than the social minimum level, supplementary social assistance is not available.

There is a considerable difference in the spread of income mutations among lower total incomes as compared to higher total incomes. Lower total incomes belong to either low incomes or short durations of disability. In both cases the new system will usually not cause such a large difference. In the short run unemployment benefits tend to have about the same level as disability benefits. Besides, in case of breadwinners and singles, if the total income is 
below the social minimum, it will be topped up to the social minimum level, both in the current system and the new system.

\section{Conclusion}

In this paper we use a microsimulation model to forecast the effects of the system change in the Dutch disability benefit law, based on full administrative data in 2003 and the imputation of other important data. This way, we can simulate the effects of policy measures. In the paper different model choices are discussed. Moreover, we show that model choice depends on the type of problem and that a dynamic population model fits the case of the disability benefits the best. It is shown that the introduction of the proposed system change decreases the number of disability benefits by more than $25 \%$ from 2020 onwards and reduces total costs by almost $€ 2$ billion or $20 \%$. Based on the better incentive structure, participation will increase and boost GDP by a similar amount so that, on average, replacement rates remain stable. Moreover microsimulation can be used to pick the winners and losers of the new system. It is shown that for almost all partially disabled that are working, the total discounted income after the system change is as large as or larger than before the system change and for the non-working it is the reverse. This clearly points out the direction of the system change towards more participation.

The model provides an improvement as compared to earlier macro analyses, especially for detailed short-term forecasts and for insight into long-term effects of policy measures for subgroups of disabled. Two results from the microsimulation model lead to an alteration of the forecasts. First, when comparing the microsimulation model to a macro cohort model, the savings of the system change in the early years are overestimated and are reduced. Second, comparing the microsimulation model to the macro model, the long-term savings appear to be underestimated. We conclude that microsimulation appears to be a superior forecasting tool as compared to the conventional macro models in a complex and dynamic environment, especially because of the in depth information of its forecasts.

However, there are many topics for future research. First, like Creedy and Kalb (2005) suggest, in a behavioural model, allowance should be made for changes in individuals' leisure as a result of a policy change, suggesting the use of a 'money metric welfare measure' rather than simply an income measure. Second, our model is a partial equilibrium model that gives a static picture of the effect of the regime change only, we do not look at what effect this extra participation will have on the labour market (wages, unemployment) as in our model the labour market is taken to be exogenous. Bourguignon and Spadaro (2005) give some suggestions to extend a partial equilibrium model to a general equilibrium model. A third topic for future research concerns the data used. Some exogenous variables, like size and composition of the labour market, have a large influence on the absolute results of the simulations, although the relative results (e.g. the savings of the new system as compared to the old system) are affected less. Also in the current approach the existence of partner income is imputed by a sample of new disability benefits with a high level of aggregation. A different approach could be the use of a model for the labour market situation of married and cohabiting partners (e.g. Henkens et. al. 2001, Nelissen, 1995).

A final important issue is the technique of predicting behavioural effects and the parameters used. The income elasticity is based on estimation of the reaction on a system change in Canada and on rather scarce Dutch data from the late nineties. Moreover, only one elasticity for all disablement beneficiaries is known. It would be interesting to investigate whether estimations are available for more recent Dutch policy measures and to estimate different elasticities for different groups of disablement beneficiaries. Logically, different 
elasticities are to be expected for fully and partially disabled and for working and nonworking disabled. The appropriate level of the discounting rate is another subject for further research but appears to be less important for the results of this particular system change.

\section{Literature}

Besseling, J., 2002. WAO: niet alle oude schoenen zijn slecht, Tijdschrift voor Bedrijfs- en Verzekeringsgeneeskunde 4 (in Dutch).

Bourguignon, F., Spadaro, A., 2005. Microsimulation as a Tool for Evaluating Redistribution Policies. Paris-Jourdan Sciences Economiques, working papepr no. 2005-02.

Caldwell, S., Morrison, R.J., 2000. Validation of longitudinal dynamic microsimulation models: experience with CORSIM and DYNACAN. Microsimulation modelling for policy analysis, Cambridge University Press.

CPB, 2001. Analyse van de voorstellen van de Adviescommissie Arbeidsongeschiktheid. CPB-Notitie 01/16 (in Dutch).

$\mathrm{CPB}, 2002$. Analyse van het SER-advies: werk maken om arbeidsongeschiktheid te voorkomen. CPB-notitie 02/35 (in Dutch).

$\mathrm{CPB}, 2004$. Vier vergezichten op Nederland, productie, arbeid en sectorstructuur in vier scenario's tot 2040. No 55 (in Dutch).

CPB, 2005. Financial incentives in Disability Insurance in the Netherlands. No 45.

Creedy, J., Kalb, G., 2005. Behavioural Microsimulation Modelling for Tax Policy Analysis in Australia: Experiences and Prospects. Melbourne Institute Working Paper Series, Working Paper No. 2/05.

Deursen, C.G.L. van et. al., 1997. ZARA-werkgeverspanel rapportage 1997. Ministerie van Sociale Zaken en Werkgelegenheid (in Dutch).

Gilbert, N., Troitzsch, K.G., 1999. Simulation for the social scientist. Open University Press.

Gruber J., 2000. Disability Insurance Benefits and Labor Supply, Journal of Political Economy, vol.108, no. 6.

Henkens, K., Grift, Y., Siegers, J., 2002. Changes in female labour supply in the Netherlands 1989-1998: The case of married and cohabiting women.

Jong, Ph. de, Thio, V., 2002. Donner versus Veldkamp, over nut en nadeel van gedeeltelijke WAO-uitkeringen (in Dutch).

Kapteyn, A. Vos, K. de, 1997. Social security and retirement in the Netherlands, working paper 6135 .

Klevmarken, N.A., 2001. Micro simulation - a tool for economic analysis. Department of Economics, Uppsala University, working paper 2001:13.

Nelissen, J.H.M., 1991. Household and Education projections by means of a microsimulation model. Economic Modelling, 8, pp 480-511.

Nelissen, J.H.M., 1993. Labour market, income formation and social security in NEDYMAS, Economic Modelling, 10, pp 225-272.

OECD, 2003. Transforming disability to ability, policies to promote work and income security for disabled people.

O’Donoghue, C., 2000. Dynamic Microsimulation: A Methodological Survey. London School of Economics.

SER, 2004. Advies Verdere uitwerking WAO-beleid - reactie op enkele kabinetsvoornemens, bijlage 8 (in Dutch).

UWV, 2004. Maandoverzicht arbeidsongeschiktheidsuitkeringen januari t/m december 2003. (in Dutch). 
A microsimulation analysis of the 2006 regime change in the Dutch disability scheme

Van Soest, A., Woittiez, I., Kapteyn, A., 1990. Labor supply, income taxes, and hours restrictions in the Netherlands. Journal of Human Resources, Vol 15, No. 3, pp 517-558.

Spielauer, M., 2002. Dynamic Microsimulation of Health Care Demand, Health Care Finance and the Economic Impact of Health Behaviour. Interim Report IR-02-032/April, International Institute for Applied Systems Analysis.

Sutherland, H., Taylor, R., Gomulka, J., 2002. Combining household income and expenditure data in policy simulations. Review of Income and Wealth, vol. 48, no. 4.

Tweede Kamer der Staten-Generaal, 2005. Wet werk en inkomen naar arbeidsvermogen, Memorie van Toelichting. Kamerstukken 30034, no. 3 (in Dutch).

Westerhout, E., 2001. Disability Risk, Disability Benefits, and Equilibrium Unemployment. International Tax and Public Finance, vol. 8, 2001, pp. 219-243. 
A microsimulation analysis of the 2006 regime change in the Dutch disability scheme

\section{Appendix A}

In this appendix, the behavioural model from paragraph 3.4 is given. The behavioural model can be described as follows. We start by distinguishing between the main groups in the system: the fully disabled, the $>35 \%$ partially disabled and the $<35 \%$ partially disabled. The fully disabled are assumed not to be able to work, the groups of partially disabled are subdivided in working and non-working. Here we see, like Creedy and Kalb (2005) mention, that behavioural microsimulation models have a lower degree of population heterogeneity than non-behavioural models because econometric estimation of the important relationships involve the use of a limited range of categories. Per group $(j)$ we define the following variables:

- $\varepsilon_{\mathrm{j}}$ : the income elasticity of group (j)

- $\delta_{\mathrm{t}}$ : the discount rate in year $(\mathrm{t})=(1-\delta)^{\mathrm{t}}$

- $\mathrm{PI}_{\mathrm{i}}$ : the pre-injury income of person (i), the annual salary earned by the person (i) at the time of the injury

- $\mathrm{I}_{\mathrm{i}, \mathrm{t}}$ : the total income of person (i) in year $(\mathrm{t})$, the total of disability benefit, employer's supplement, wage, unemployment benefit, supplementary benefits and social assistance.

- $\mathrm{N}_{\mathrm{j}}$ : the number of benefits in group $(\mathrm{j})$

The aggregate behavioural effect for group (j) can be computed by computing the change in group replacement rates and multiplying by the group elasticity:

- Total discounted income of group (j) in the current system:

$$
\mathrm{DI}_{\mathrm{j}}=\sum_{i, t} I_{i, t} \delta_{t} \quad \forall i \in j
$$

- Total discounted income of group (j) in the new system:

$$
\mathrm{DI}_{\mathrm{j}}{ }^{\prime}=\sum_{i, t} I_{i, t}^{\prime} \delta_{t}^{\prime} \quad \forall i \in j
$$

- Total discounted pre-injury income of group (j):

$$
\mathrm{DPI}_{\mathrm{j}}=\sum_{i, t} P I_{i, t} \delta_{t} \quad \forall i \in j
$$

- Average replacement rate in current system:

$$
\mathrm{RR}_{\mathrm{j}}=\frac{D I_{j}}{D P I_{j}}
$$

- Average replacement rate in new system:

$$
\mathrm{RR}_{\mathrm{j}}{ }^{\prime}=\frac{D I_{j}^{\prime}}{D P I_{j}}
$$

- Number of benefits of group (j) in the new system:

$$
\mathrm{N}_{\mathrm{j}}^{\prime}=\mathrm{N}_{\mathrm{j}} *\left(\mathrm{RR}_{\mathrm{j}}-\mathrm{RR}_{\mathrm{j}}\right) * \varepsilon_{\mathrm{j}}
$$

Because of our assumption that the change in replacement rate does not influence the number of benefits, we have to adjust the group totals as follows:

$$
\text { - } \mathrm{N}=\sum_{j} N_{j}
$$


A microsimulation analysis of the 2006 regime change in the Dutch disability scheme

- $\quad \mathrm{N}^{\prime}=\sum_{j} N_{j}^{\prime}$

- $\mathrm{N}_{\mathrm{j}}{ }^{\prime \prime}=\frac{N}{N^{\prime}} * N_{j}^{\prime}$

If the replacement rate of group (j) decreases because of a policy measure (so if $R R_{j}{ }^{\prime}<R R_{j}$ ), the number of working partially disabled in group (j) increases by $\left(\mathrm{N}_{\mathrm{j}} \mathrm{N}_{\mathrm{j}}\right)$. As the total number of benefits in group $(\mathrm{j})$ does not change, the number of unemployed partially disabled in group (j) decreases by the same amount. 
A microsimulation analysis of the 2006 regime change in the Dutch disability scheme

\section{Appendix B}

In this appendix, the formulas from figure 3 are explained.

\section{Disability benefit (WAO)}

The level of the disability benefit for individual (i) at time (t) is determined in the first phase, based on grade of disability ( $\mathrm{gd}$ ) and personal wage ( $\mathrm{pw}$ ) previously earned before disability:

$$
\begin{gathered}
\left.\mathbf{W A O}_{\mathrm{i}, \mathrm{t}}=\mathbf{F}_{\mathbf{1}} \mathbf{( a g e}_{\mathbf{i}}, \mathbf{g d}_{\mathrm{i}, \mathrm{t}} ; \mathbf{p w}_{\mathrm{i}}\right) \\
\begin{cases}0.7 * \mathrm{pw}_{\mathrm{i}} ; & \text { if } 80 \leq \mathrm{gd}_{\mathrm{i}, \mathrm{t}} \leq 100 \\
0.5075 * \mathrm{pw}_{\mathrm{i}} ; & \text { if } 65 \leq \mathrm{gd}_{\mathrm{i}, \mathrm{t}} \leq 80 \\
0.42 * \mathrm{pw}_{\mathrm{i}} ; & \text { if } 55 \leq \mathrm{gd}_{\mathrm{i}, \mathrm{t}} \leq 65 \\
0.35 * \mathrm{pw}_{\mathrm{i}} ; & \text { if } 45 \leq \mathrm{gd}_{\mathrm{i}, \mathrm{t}} \leq 55 \\
0.28 * \mathrm{pw}_{\mathrm{i}} ; & \text { if } 35 \leq \mathrm{gd}_{\mathrm{i}, \mathrm{t}} \leq 45 \\
0.21 * \mathrm{pw}_{\mathrm{i}} ; & \text { if } 25 \leq \mathrm{gd}_{\mathrm{i}, \mathrm{t}} \leq 35 \\
0.14 * \mathrm{pw}_{\mathrm{i}} ; & \text { if } 15 \leq \mathrm{gd}_{\mathrm{i}, \mathrm{t}} \leq 25\end{cases}
\end{gathered}
$$

Equation (1) represents the wage in the first phase of the benefit. The duration of this benefit depends on the age of the recipient upon becoming disabled.

$$
\begin{cases}\text { For } 6 \text { months } & \text { if } 33 \leq \text { age }_{\mathrm{i}}<37 \\ \text { For 1 year } & \text { if } 38 \leq \text { age }_{\mathrm{i}}<42 \\ \text { For 1.5 years } & \text { if } 43 \leq \mathrm{age}_{\mathrm{i}}<47 \\ \text { For } 2 \text { years } & \text { if } 48 \leq \text { age }_{\mathrm{i}}<52 \\ \text { For } 3 \text { years } & \text { if } 53 \leq \text { age }_{\mathrm{i}}<57 \\ \text { For } 6 \text { years } & \text { if } 58 \leq \text { age }_{\mathrm{i}}\end{cases}
$$

The level of disability benefit in the second phase is based on a supplement on top of seventy percent of the minimum wage level. This supplement is equal to two percent of the difference between personal wage and the minimum wage $(\mathrm{mw})$ times the number of years the recipient, on the day of sickness, is older than 15 years of age.

$$
\mathbf{W A O}_{\mathbf{i}, \mathbf{t}}=\mathbf{0 . 7} *\left(\mathbf{0 . 0 2} *\left(\mathbf{p w}_{\mathbf{i}}-\mathbf{m w}\right)(\text { age }-15)\right)+\mathbf{0 . 7} * \mathbf{m w}
$$

\section{Unemployment benefit (WW)}

The unemployment benefit is dependent on the working status (ws) of recipient (i) at time $(\mathrm{t})$, the age, the grade of disability $(\mathrm{gd})$, the working history (wh) and the level of personal wage when becoming disabled $(\mathrm{pw})$ :

$$
\text { WWi,t = F3(wsi,t ; whi ; gdi,t ; pwi,t) = }
$$


$0.1925 * \mathrm{pw}_{\mathrm{i}} ; \quad$ if $65 \leq \mathrm{gd}_{\mathrm{i}, \mathrm{t}} \leq 80$

$0.28 * \mathrm{pw}_{\mathrm{i}} ; \quad$ if $55 \leq \mathrm{gd}_{\mathrm{i}, \mathrm{t}} \leq 65$

$0.35 * \mathrm{pw}_{\mathrm{i}} ; \quad$ if $45 \leq \mathrm{gd}_{\mathrm{i}, \mathrm{t}} \leq 55$

$0.42 * \mathrm{pw}_{\mathrm{i}} ; \quad$ if $35 \leq \mathrm{gd}_{\mathrm{i}, \mathrm{t}} \leq 45$

$0.49 * \mathrm{pw}_{\mathrm{i}} ; \quad$ if $25 \leq \mathrm{gd}_{\mathrm{i}, \mathrm{t}} \leq 35$

$0.56 * \mathrm{pw}_{\mathrm{i}} ; \quad$ if $15 \leq \mathrm{gd}_{\mathrm{i}, \mathrm{t}} \leq 25$

The duration of the unemployment benefit depends on the working history as follows:

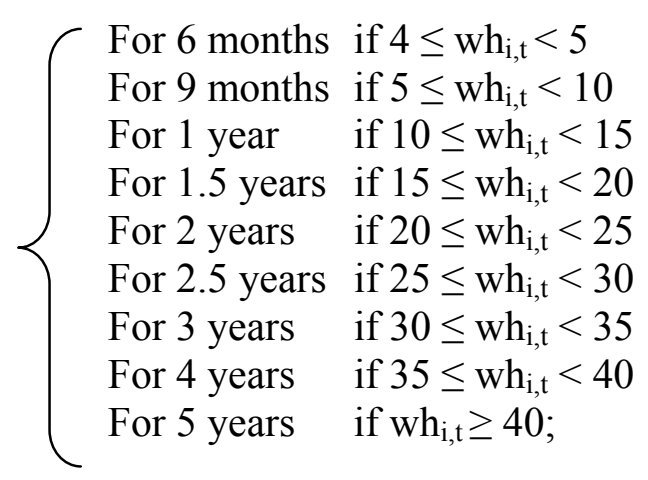

If a person has a grade of disability of at least $80 \%$ with a disability benefit, then he is excluded from receiving an unemployment benefit. Recipients above the age of 65 are also excluded. The working history is the total number of working years which determines the duration of the benefit.

\section{Supplementary Benefits Act (TW)}

The level of supplementary benefit for individual (i) at time ( $t$ ) is determined by the difference between the total amount of disability benefit/unemployment benefit/wage ( tot $\left._{i, 1}\right)$ and the social minimum (sw), which equals $70 \%$ of the minimum wage for a single, $90 \%$ of the minimum wage for a single with a child below the age of 18 and $100 \%$ of the minimum wage for a breadwinner:

$$
\begin{aligned}
& \mathbf{T W}_{\mathrm{i}, \mathrm{t}}=\mathbf{F}_{\mathbf{4}}\left(\mathbf{h h}_{\mathrm{i}} ; \mathbf{W A O} \mathbf{O}_{\mathrm{i}, \mathrm{t}} ; \mathbf{W} \mathbf{W}_{\mathrm{i}, \mathrm{t}}\right) \\
& = \begin{cases}\mathrm{sw}-\text { tot }_{\mathrm{i}, 1} ; & \text { when married/living together } \\
90 \%\left(\mathrm{sw}-\text { tot }_{\mathrm{i}, 1}\right) ; & \text { when single with child below the age of } 18 \\
70 \%\left(\mathrm{sw}-\text { tot }_{\mathrm{i}, 1}\right) ; & \text { when single/no kids }\end{cases}
\end{aligned}
$$

However, the supplementary benefit is limited by 2 ceilings. First, the supplement cannot exceed $30 \%$ of the benefit itself. Second, the total benefit, including the supplement, cannot exceed the previous wage.

\section{Provision for Older and Partly Disabled Unemployed Employees (IOAW)}

The level of IOAW benefit for individual (i) at time ( $\mathrm{t}$ ) is also determined by the difference between the total amount of disability benefit/supplementary benefit/wage $\left(\right.$ tot $\left._{\mathrm{i}, 2}\right)$ and the social minimum $(\mathrm{sm})$ :

$$
\operatorname{IOAW}_{\mathrm{i}, \mathrm{t}}=\mathrm{F}_{5}\left(\mathrm{hh}_{\mathrm{i}} ; \mathrm{WAO}_{\mathrm{i}, \mathrm{t}} ; \mathrm{WW}_{\mathrm{i}, \mathrm{t}} ; \mathrm{TW}_{\mathrm{i}, \mathrm{t}}\right)
$$


A microsimulation analysis of the 2006 regime change in the Dutch disability scheme

$$
= \begin{cases}\mathrm{sw}-\text { tot }_{\mathrm{i}, 2} ; & \text { when married/living together } \\ 90 \%\left(\mathrm{sw}-\text { tot }_{\mathrm{i}, 2}\right) ; & \text { when single with child below the age of } 18 \\ 70 \%\left(\mathrm{sw}-\text { tot }_{\mathrm{i}, 2}\right) ; & \text { when single/no kids }\end{cases}
$$

